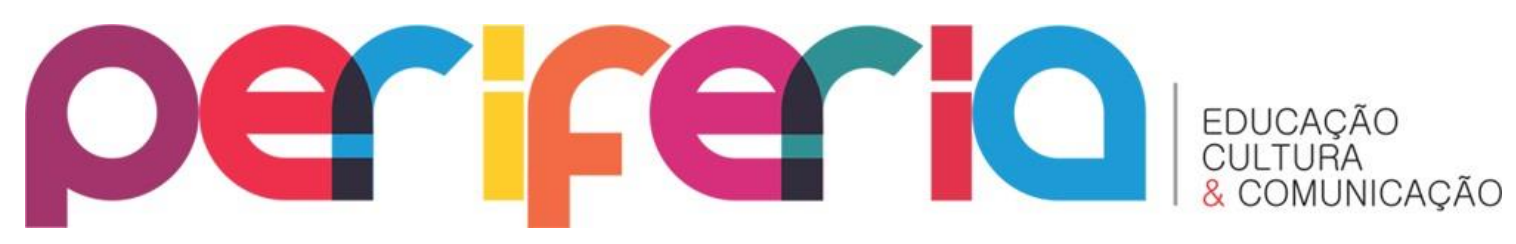

\title{
DIZERES DE UMA PROFESSORA SOBRE A ESCOLARIZAÇÃO DE SURDOS NO CONTEXTO DA INCLUSÃO ESCOLAR EM BREVES-PARÁ
}

\author{
Huber Kline Guedes Lobato ${ }^{1}$ \\ Universidade Federal do Pará
}

\section{Resumo}

Neste artigo questionamos: quais os dizeres de uma professora sobre a escolarização de alunos Surdos em Breves - Pará? A partir desta inquietação objetivamos identificar, com este estudo, o perfil desta professora e analisar seus dizeres acerca da escolarização de alunos Surdos que estudam em escola inclusiva em Breves-Pará. Este trabalho é fruto de uma pesquisa de abordagem qualitativa com uso de mapas conceituais. Em contato com a professora realizamos entrevista individual, com auxílio de um roteiro, no espaço de uma sala regular de uma escola inclusiva. Fizemos a análise do corpus das respostas da entrevistada, utilizando algumas técnicas de análise de conteúdo. Os resultados deste estudo revelam que: há um distanciamento entre professores do ensino regular, outros profissionais e de alguns familiares com a escolarização do aluno Surdo; a Libras e recursos visuais ou em Libras estão mais presentes no AEE em SRM; o professor de AEE em SRM possui atribuições abrangentes e excesso de funções no trabalho com Surdos; e há a ausência do profissional intérprete de Libras, assim como de alguns familiares de Surdos na escola. Concluímos ser preciso pensar ações educacionais que reconheçam os Surdos a partir de suas diferenças linguísticas e comunicacionais, com mudanças estruturais na escola, que possibilite um ensino bilíngue, que vai além do uso e difusão da língua de sinais, visando a garantia de acesso e permanência dos Surdos com seus pares no âmbito escolar.

Palavras-chave: inclusão escolar; aluno surdo; ensino-aprendizagem

\footnotetext{
${ }^{1}$ Mestre em Educação pela Universidade do Estado do Pará. Professor Assistente do Instituto de Letras e Comunicação da Universidade Federal do Pará. Coordenador do Curso de Letras Libras e Língua Portuguesa como segunda língua para surdos da UFPA. Vice-líder do Grupo de Estudos e Pesquisas em Educação de Surdos - GEPESUR. huberkline@ufpa.br
} 


\title{
periferio
}

SAYS FROM A TEACHER ABOUT THE SCHOOLING OF DEAFS IN THE CONTEXT OF SCHOOL INCLUSION IN BREVES-PARÁ

\begin{abstract}
In this paper we question: what are the sayings of a teacher about the schooling of deaf students in the city of Breves, Pará State, in Brazil? From this concern we aim to identify, with this study, the profile of this teacher and analyze her comments about schooling of deaf students who study in an inclusive school in Breves, Pará, Brazil. This work is the result of a qualitative research using conceptual maps. In contact with the teacher we conducted an individual interview, with the help of a script, in the space of a regular room of an inclusive school. We did the corpus analysis of the interviewee's answers, using some techniques of content analysis. The results of this study reveal that: there is a gap between regular teachers, other professionals and some relatives with the schooling of the deaf student; the Brazilian Sign Language (Libras) and visuals or in Libras are more present in the Specialized Educational Service (AEE) in Multifunction resource room (SRM); the AEE teacher in SRM has extensive assignments and overwork in deaf work; and there is the absence of the professional to interpreter of Libras, as well as of some deaf relatives in the school. We conclude that it is necessary to think about educational actions that recognize the deaf from their linguistic and communicational differences, with structural changes in the school, that allows a bilingual education that goes beyond the use and diffusion of sign language, aiming at guaranteeing access and permanence of the deaf with their peers in school.
\end{abstract}

Keywords: scholar inclusion; deaf student; teaching-learning 


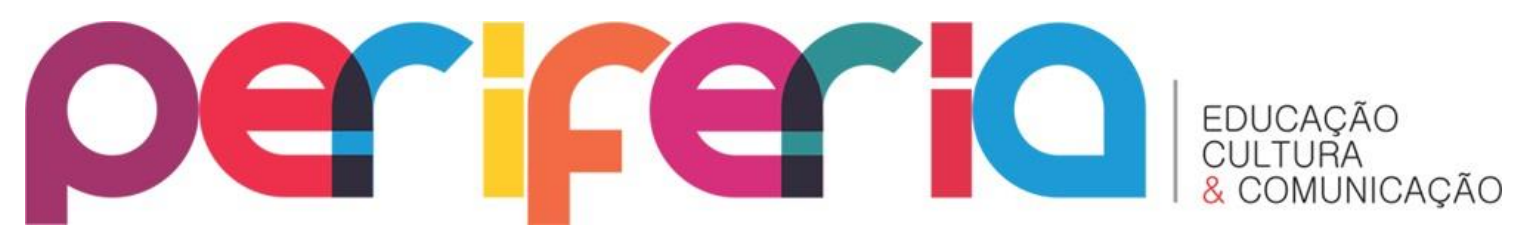

\section{INTRODUÇÃO}

Neste artigo apresentamos um recorte da pesquisa que configurou a dissertação de mestrado intitulada "Representações Sociais de professoras a respeito do Atendimento Educacional Especializado para alunos Surdos", desenvolvida no período de 2013 a 2015, no Programa de Pós-Graduação em Educação da Universidade do Estado do Pará (PPGED-UEPA).

A pesquisa foi realizada em Breves-Pará, que é um município com uma área de $9.550,513 \mathrm{~km}^{2}$ e fica distante à $12 \mathrm{~h}$ de navio da capital Belém. De acordo com dados do Censo Demográfico de 2014, do Instituto Brasileiro de Geografia e Estatística (IBGE), Breves possui uma população de 97.351 habitantes, sendo considerada a cidade mais desenvolvida economicamente da região do Marajó.

A partir de dados do Centro de Atendimento Educacional Especializado (CAEE) Hallef Pinheiro Vasconcelos e da Secretaria Municipal de Educação (SEMED) o município de Breves possui 12 escolas de educação infantil, 10 de ensino fundamental ( $1^{\circ}$ ao $5^{\circ}$ ano) e 11 de ensino fundamental ( $6^{\circ}$ ao $9^{\circ}$ ano), perfazendo um total de 33 estabelecimentos de ensino que são administrados pela SEMED/Breves. No âmbito destes estabelecimentos os alunos estão distribuídos em turmas regulares, totalizando 31.576 alunos matriculados na educação infantil e ensino fundamental. Destes alunos, há a presença de 567 inclusos no ensino regular, sendo que 39 são Surdos. ${ }^{2}$

Em Breves existem 22 Salas de Recursos Multifuncionais (SRM) em escolas da cidade e do campo, sendo que apenas 11 encontram-se em uso. Isto ocorre, "em virtude da ausência de espaço físico (sala) para implantar o Programa Sala de Recurso Multifuncional e professor concursado com formação em Educação Especial, principalmente, para o campo" (COMISSÃO DE ELABORAÇÃO DO PME - BREVES, 2015, p. 115).

\footnotetext{
2 Utilizamos o termo "Surdo" ou "Surdos" escrito com inicial maiúscula, pois embasado em Dorziat (2009), buscamos marcar uma concepção política de surdez, vista para além do fator biológico ou clínico-terapêutico.
} 


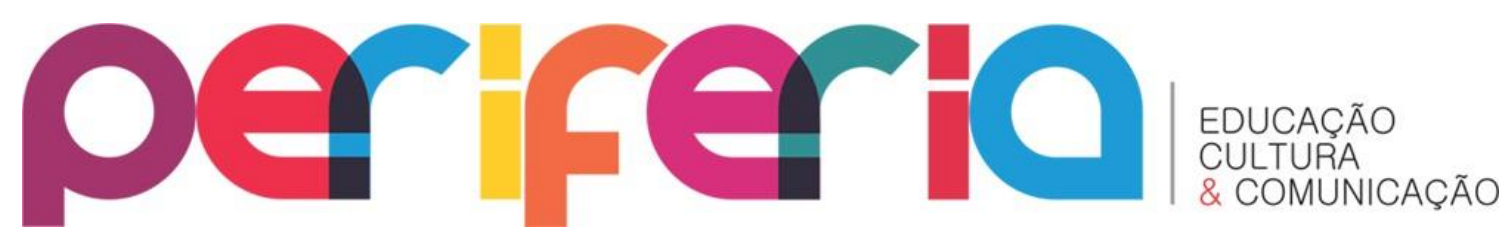

Por meio de informações do CAEE nas SRM há a presença de professores que atuam em duplas ou de forma individual nestas salas; e que existem professores itinerantes e professores cuidadores ou de apoio na cidade e no campo ${ }^{3}$ que auxiliam os alunos da educação especial em escolas regulares.

Em Breves, a Libras se faz presente na sala de aula regular em algumas escolas por meio de projetos educacionais, ${ }^{4}$ porém esta língua é desenvolvida de forma mais efetiva no contexto do Atendimento Educacional Especializado (AEE) nas salas de recursos multifuncionais. Desta forma, na escola que se diz inclusiva, o AEE torna-se substitutivo e não complementar a escolarização do aluno Surdo, assim, este aluno aprende e se desenvolve significativamente no $A E E$, ao passo que na sala de aula regular inclusiva enfrenta barreiras no processo de escolarização.

Com base nestes pressupostos, destacamos que este estudo surgiu pelo fato do autor ter realizado atividades pedagógicas na área da educação de Surdos no município de Breves, e assim, ter estabelecido contato com professores e professoras que lidam com alunos Surdos em turmas inclusivas. Assim, no presente estudo levantamos como questão-problema: quais os dizeres de uma professora sobre a escolarização de alunos Surdos em Breves Pará? Com isso, buscamos identificar o perfil de uma professora e analisar seus dizeres acerca da escolarização de alunos Surdos que estudam em escola inclusiva em Breves-Pará.

\footnotetext{
${ }^{3}$ Em Breves o cargo de professor cuidador e professor de apoio insere-se na função de professor especialista em Educação Especial - Apoio Pedagógico e/ou Atendimento Múltiplo, de acordo com concurso público - edital $n^{\circ}$ 01/2013/PMB.

${ }^{4} \mathrm{Em}$ Breves o CAEE desenvolve projetos que possuem ações voltadas ao processo ensinoaprendizagem da Libras em turmas regulares do $1^{\circ}$ ao $5^{\circ}$ ano do ensino fundamental, como é o caso dos projetos "Escolibras" e "Na palma da mão", projetos de duas escolas públicas do município, tais escolas são: Escola Dr. Lauro Sodré e Escola Prof ${ }^{a}$ Emerentina Moreira de Souza.
} 


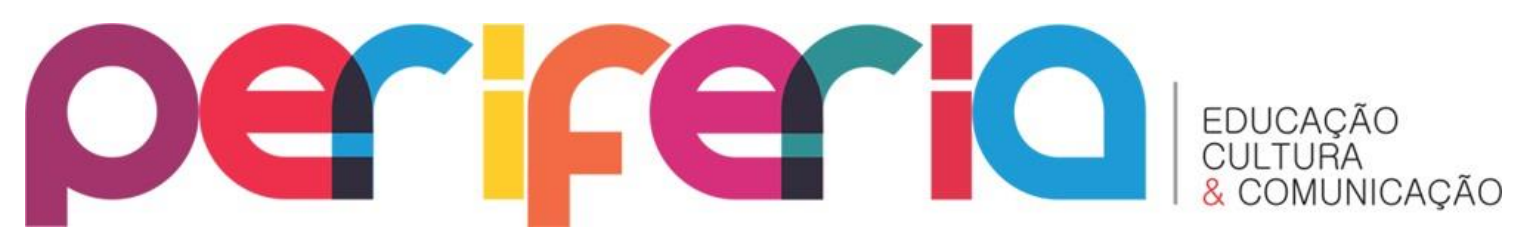

\section{PERCURSO METODOLÓGICO}

O presente estudo foi desenvolvido por meio de pesquisa de abordagem qualitativa, sendo este tipo de pesquisa aquela que, para Minayo (1994, p. 21 22):

Responde a questões muito particulares. Ela se preocupa, nas ciências sociais, com um nível de realidade que não pode ser quantificado, ou seja, ela trabalha com o universo de significados, motivos, aspirações, crenças, valores e atitudes, o que corresponde a um espaço mais profundo das relações dos processos e dos fenômenos que não podem ser reduzidos à operacionalização de variáveis.

Durante a pesquisa utilizamos como estratégia de obtenção de dados o uso de mapas conceituais que, conforme Moreira e Masini (1982, p. 7-8) é uma técnica advinda da Teoria da Aprendizagem Significativa (TAS) de David Ausubel que descreve esta teoria como um processo que:

Ocorre quando a nova informação ancora-se em conceitos relevantes preexistentes na estrutura cognitiva de quem aprende. Ausubel vê o armazenamento de informações no cérebro humano como sendo altamente organizado, formando uma hierarquia conceitual na qual elementos mais específicos de conhecimentos são ligados (e assimilados) a conceitos mais gerais, mais inclusivos. Estrutura cognitiva significa, portanto, uma estrutura hierárquica de conceitos que são abstrações da experiência do indivíduo.

De acordo com a teoria ausubeliana, a aprendizagem significativa ocorre quando é influenciada a partir dos conhecimentos prévios que podem ser representados por meio de mapas conceituais. Trata-se de uma "técnica desenvolvida em meados da década de 1970 por Joseph Novak e seus colaboradores na Universidade de Cornell nos Estados Unidos" (MOREIRA, 2011, p. 129). A seguir apresentamos um exemplo de mapa conceitual: 


\section{per
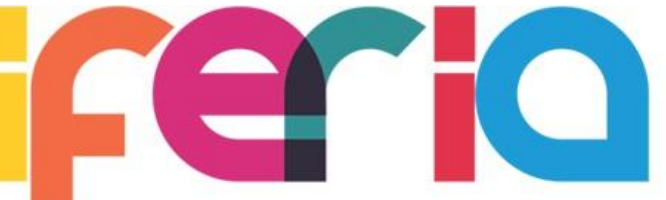 \\ EDUCAÇÃO \\ CULTURA}

Figura 1: modelo de mapa conceitual

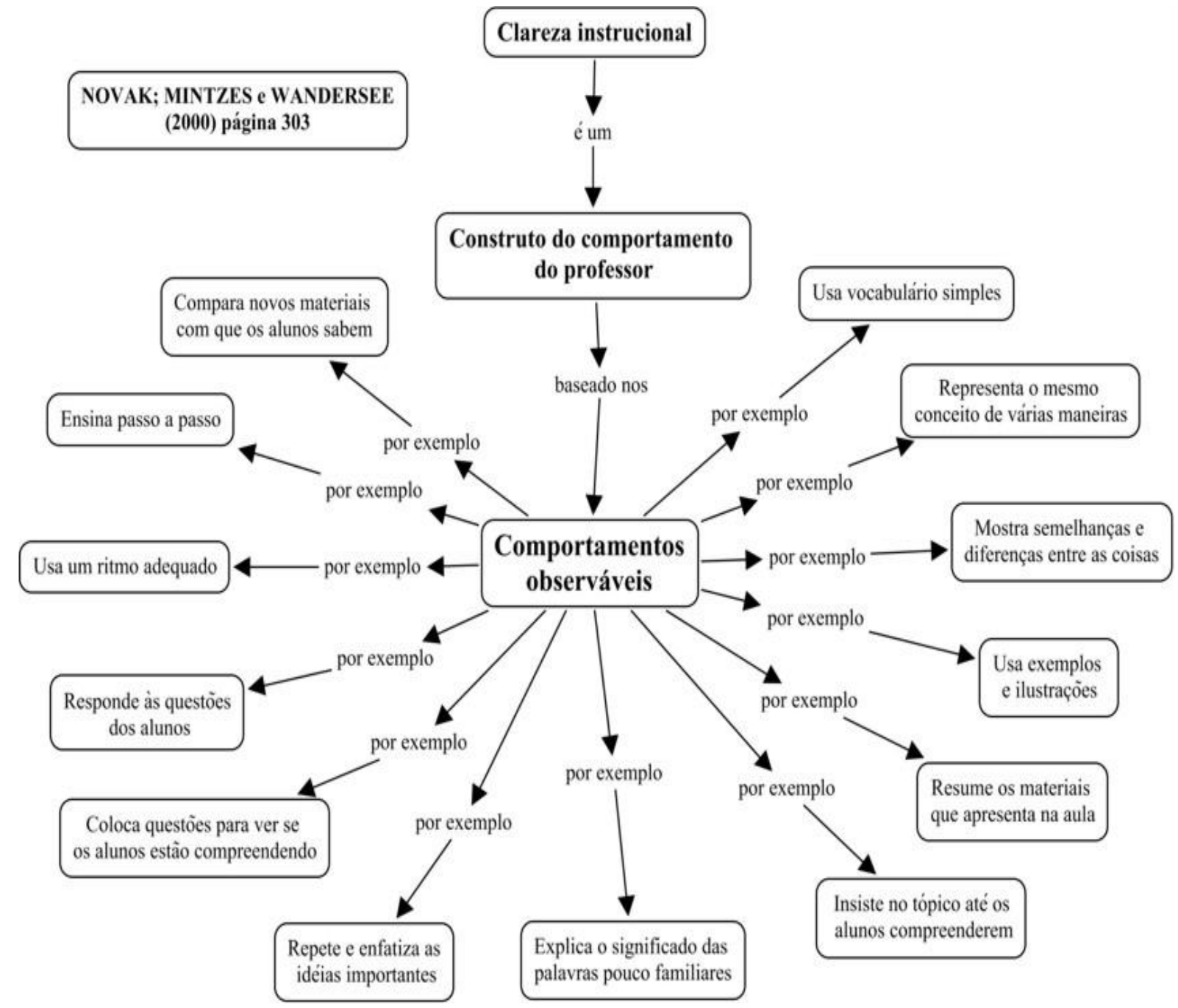

Fonte: TAVARES, 2007, p. 79.

Esses mapas, apesar de serem usados como instrumento facilitador da aprendizagem, possibilitando uma oportunidade de estudantes aprenderem conteúdos complexos de forma rápida e prática, também servem, segundo Tavares (2007) "para um especialista tornar mais clara as conexões que ele percebe entre os conceitos sobre determinado tema" (p. 74). Com base nesta função é que utilizamos os mapas conceituais neste estudo, no sentido de visualizar os dizeres de uma professora que atuou como participante na pesquisa em Breves-Pará. 


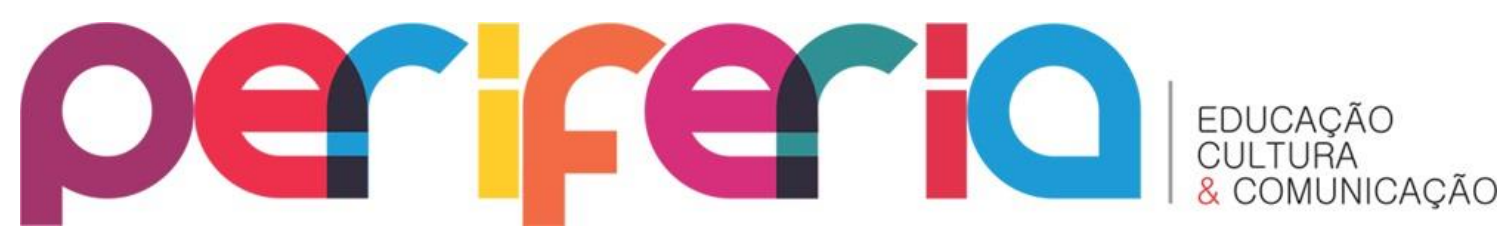

Segundo Moreira (2006, p. 2) os mapas conceituais "podem ser interpretados como diagramas hierárquicos que procuram refletir a organização conceitual de um corpo de conhecimento ou parte dele" tornando mais fáceis a percepção e compreensão de determinados conceitos, pois neles existem aproximações entre a memória visual e as imagens (palavras) de ligação que são apresentadas nos mapas.

Junto à professora realizamos entrevista individual, que é "uma técnica de investigação baseada em perguntas que são dirigidas a pessoas previamente escolhidas" (LUDWIG, 2009, p. 65). Sobre a tipologia da entrevista, utilizamos a entrevista semiestruturada, "que se baseia em questões específicas, porém sem ordenamento rígido” (LUDWIG, 2009, p. 66).

Para seguirmos uma sequência durante a entrevista, usamos um roteiro, sendo que a fala da entrevistada foi gravada em aparelho Smartphone LG-L5 e o local de realização da entrevista foram as dependências de uma sala regular, espaço este em que a professora realizava suas atividades educativas.

Em nossa pesquisa entrevistamos uma professora com o perfil que será descrito a partir do quadro que se segue, em que revelamos o nome fictício, a idade, a escolaridade, a formação e as suas experiências docentes.

Quadro 1: Professora participante da pesquisa

\begin{tabular}{|c|c|c|c|c|}
\hline NOME & IDADE & ESCOLARIDADE & FORMAÇÃO & EXPERIÊNCIA DOCENTE \\
\hline $\begin{array}{c}\text { Olga } \\
\text { Odete }\end{array}$ & $\begin{array}{c}45 \\
\text { anos. }\end{array}$ & $\begin{array}{c}\text { Nível Superior } \\
\text { completo. }\end{array}$ & $\begin{array}{c}\text { Licenciada em } \\
\text { Pedagogia e } \\
\text { Especialista } \\
\text { em Educação } \\
\text { Especial. }\end{array}$ & $\begin{array}{c}\text { Atua há } 7 \text { anos como professora do } \\
1^{\circ} \text { ao } 5^{\circ} \text { ano do Ensino } \\
\text { Fundamental, já atuou em turmas } \\
\text { do } 6^{\circ} 9^{\circ} \text { ano e desde } 2010 \\
\text { desenvolve atividades em SRM com } \\
\text { alunos Surdos. }\end{array}$ \\
\hline
\end{tabular}

Fonte: elaboração própria, 2015.

Olga Odete: é uma professora que atua no AEE, trabalhando com alunos Surdos no contraturno. Em seu trabalho utiliza diversas metodologias, como: vídeos em Libras, histórias e narrativas em Libras, teatro, jogos entre outras. A professora prioriza sempre a questão visual em seu trabalho, utilizando a 


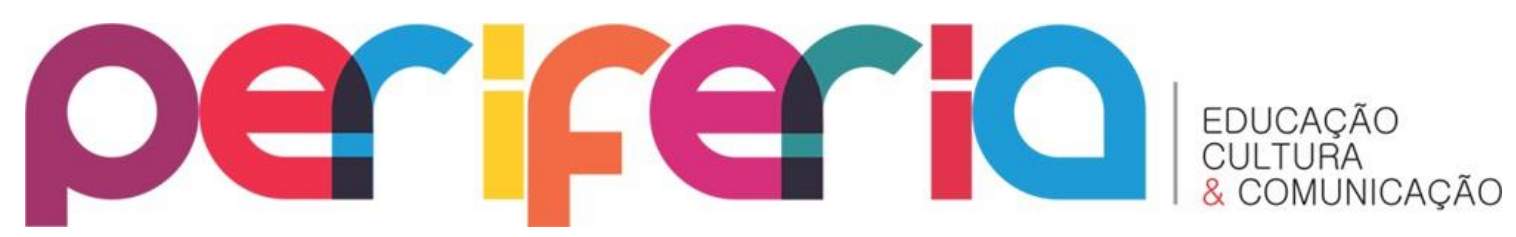

Libras como principal recurso de comunicação. Já participou de diversas oficinas, palestras de instituições locais e regionais, assim como, de momentos de formação e orientação ofertados por parte do CAEE em Breves.

Para análise dos dados, recorremos a Bardin, (2011), e fizemos a análise do corpus das respostas da participante de nosso estudo, mediante o uso de algumas técnicas de análise de conteúdo, com o seguinte caminho: leitura flutuante da fala do sujeito, recorte das unidades, criação e validação de categorias, assim como interpretação e análise das categorias a partir dos recortes das unidades temáticas.

\section{ASPECTOS CONCEITUAIS SOBRE A ESCOLARIZAÇÃO DE SURDOS NO CONTEXTO DA INCLUSÃO ESCOLAR}

Conforme Oliveira (2004) o paradigma da inclusão, que vemos surgir na década de 1990, visa a inclusão das pessoas com necessidades especiais ao sistema comum de ensino rompendo a discriminação destas pessoas na escola, que estava configurada por meio das "classes especiais". Este paradigma tem como pressuposto uma "educação para todos", ou seja, uma educação que respeite as distintas peculiaridades sociais e individuais.

A partir das propostas de inclusão educacional, busca-se a inserção de alunos com necessidades educacionais especiais nas classes comuns e, com isso, superar as dicotomias existentes entre o ensino comum e o ensino especial. Contudo, Oliveira (2004) adverte que apesar deste "conceito estar contido em um enfoque crítico-institucional, que pressupõe mudanças estruturais na escola, é necessário problematizar-se este conceito de inclusão por ser ambíguo" (p. 71).

Consideramos também ambíguo o conceito de inclusão, pois no seio deste conceito encontra-se o seu oposto, a exclusão, ou seja, se há uma proposta de educação inclusiva, inferimos que haja a existência de excluídos, tanto no âmbito social, quanto no âmbito educacional. Além do que, a ideia 


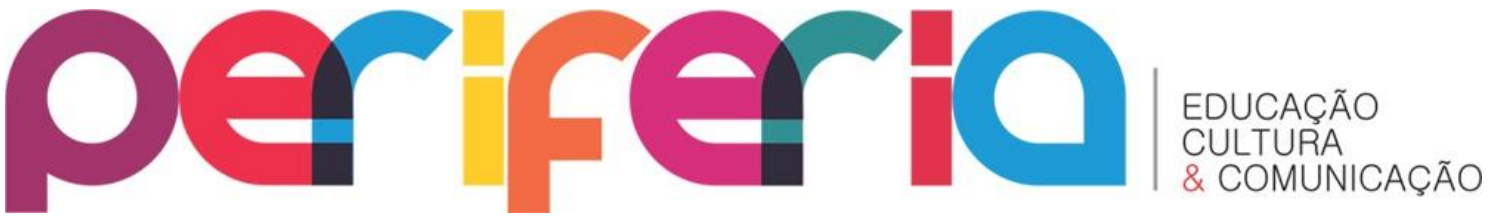

de inclusão traz em suas entrelinhas a concepção de normalização de pessoas tidas como "anormais".

Bentes e Hayashi (2012) já retratam que "os discursos falaciosos da inclusão podem assumir a ideologia da normalização e desejar que a pessoa seja assimilada e deixe de ser deficiente, tornando-se normal" (p. 142). Com isso, a escola que almeja ser inclusiva, mediante a inserção de alunos com "limitações" em classes regulares, passa a ser uma escola excludente. Oliveira (2004) diz que "romper essa situação de exclusão dessas pessoas, no sistema educacional, exige novas diretrizes filosóficas e pedagógicas na educação" (p. 75).

Com base nisto, mencionamos que a escola pública e por sua vez as escolas que se dizem inclusivas, excluem não somente os alunos com necessidades educacionais especiais, mas conforme aponta Oliveira (2004), são excluídos,

Todos/as aqueles/as que apresentam dificuldades na aprendizagem cognitiva de apreensão dos conteúdos escolares e que, portanto, fogem do modelo tradicional escolar estabelecido. A escola pública no processo pedagógico, está direcionada para dentro de si, valorizando o/a aluno/a que apresenta dificuldades e limitações na aprendizagem, não levando em conta a estrutura global do sistema social e educacional (p. 224).

Oliveira (2004) afirma que as práticas educativas pautadas em propostas de inclusão escolar fazem parte de uma conjuntura nacional de diretrizes governamentais do sistema educacional, mas que no seio escolar, podem existir outros olhares que reproduzem os discursos oficiais ou negam tais discursos, por isso:

É preciso deixar claro que o discurso inclusivo faz parte da política educacional no Brasil, numa perspectiva liberal, mas que a inclusão faz parte, também, do discurso dos que lutam por uma educação para todos, por uma escola que não negue seu papel educacional fundamental, que é o de incluir (p. 85). 


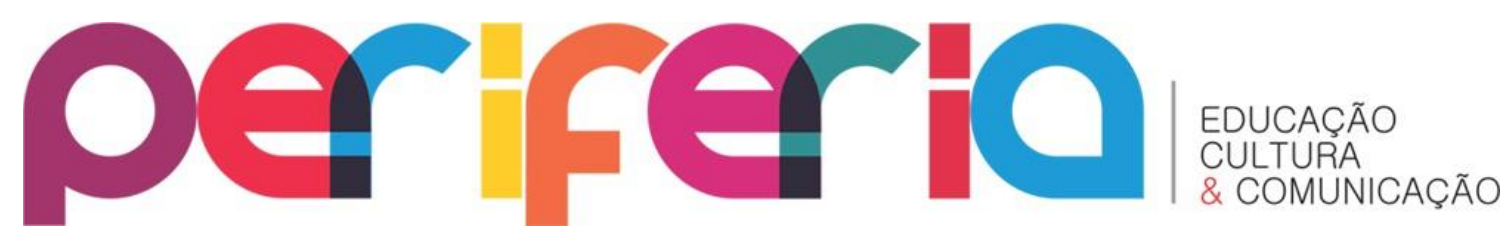

Ao considerar essa perspectiva, continuamos a concordar com o pensamento de Oliveira (2004) quando diz que "a escola pública é uma instituição contraditória, porque apresenta tanto representações e práticas de exclusão como representações e práticas inclusivas e de transformação" (p. 224). No âmbito dessa exclusão há a presença de pessoas que possuem algum tipo de deficiência, inclusive pessoas Surdas.

Segundo Lacerda e Lodi (2009) a pessoa Surda no contexto da escola que se diz inclusiva, de certa forma "não é atendida em sua condição sociolinguística especial, não são feitas alterações metodológicas que levem em conta a surdez, e o currículo não é repensado, culminando em um desajuste socioeducacional (p. 15).

A este respeito Ferreira e Zampieri (2009) apontam que "é imprescindível que o professor ouvinte obtenha mais conhecimentos da Libras para que seja possível auxiliar os alunos Surdos nas questões do cotidiano da sala de aula” (p. 110). Nesta escola também há a necessidade de ter o profissional intérprete de Libras para mediar a comunicação entre Surdos e ouvintes.

Sendo assim, evidenciamos o posicionamento de Campos (2013) quando diz que "quando há carência de profissionais intérpretes, a interação entre Surdos e pessoas que desconhecem a língua de sinais fica prejudicada" (p. 57).

Desta forma, com base nas leituras de estudiosos da área da educação de Surdos como Anjos, et al (2014), Campos (2013), Delevati (2012), Ferreira e Zampieri (2009), Góes e Barbeti (2009), Lacerda e Lodi (2009) que defendem a transformação do modelo de escola inclusiva, ratificamos a relevância deste estudo, no sentido de realizarmos reflexões sobre a escolarização do aluno Surdo no contexto da escola regular que se diz inclusiva em Breves - Pará.

Nesta pesquisa o mapa conceitual consistiu em instrumento metodológico que foi usado com a professora participantes de nossa pesquisa durante a entrevista realizada no dia 19/03/2015. Perceberemos no mapa 


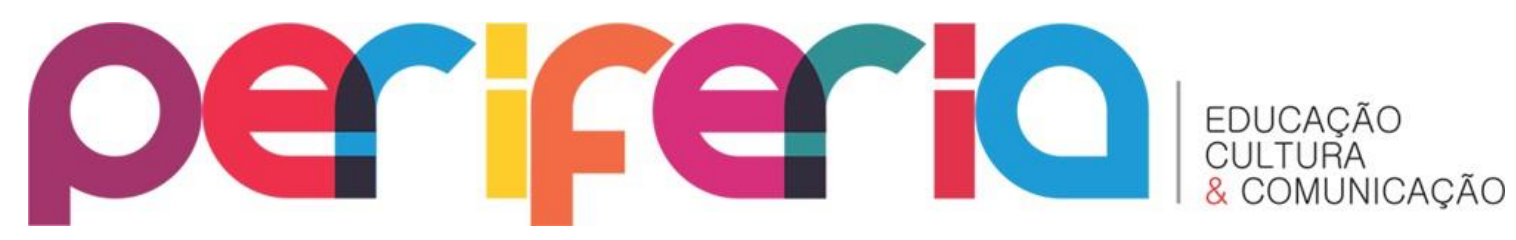

conceitual elaborado pela professora a existência de um grande número de conexões entre os conceitos relacionados a escolarização de Surdos, revelando a familiaridade da entrevistada com o tema considerado.

\section{DIZERES DA PROFESSORA SOBRE A ESCOLARIZAÇÃO DE ALUNOS SURDOS EM BREVES - PARÁ}

Neste tópico apresentamos o mapa conceitual elaborado pela professora Olga Odete, que organizou suas informações em um mapa do tipo sistema entrada e saída. Tavares (2007) revela que neste mapa as informações são organizadas com o acréscimo da imposição das possibilidades "entrada" e "saída" em seus conceitos, ou seja, existem correlações entre conceitos neste mapa.

Figura 2: Mapa Conceitual elaborado pela professora

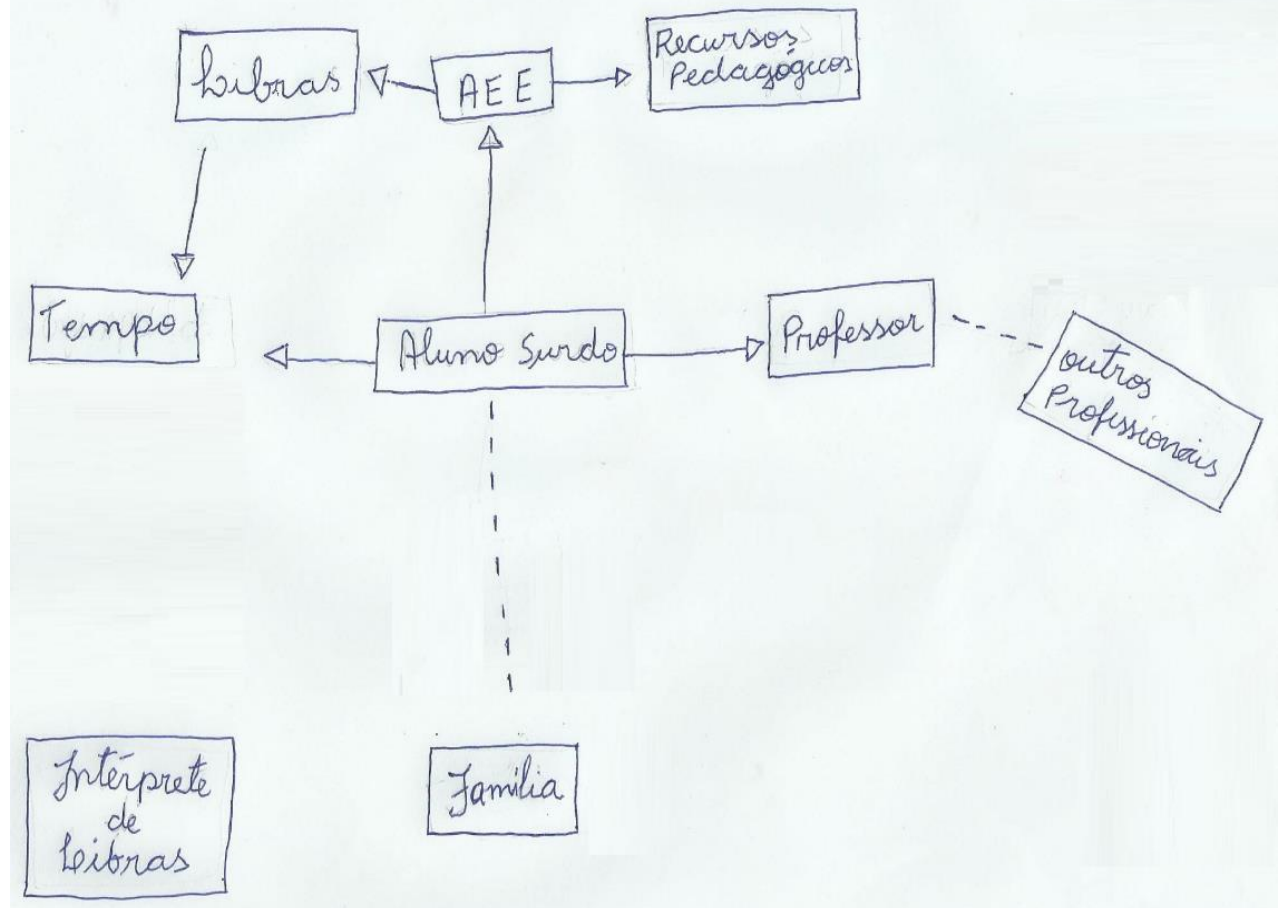

Fonte: arquivo pessoal, 2015. 


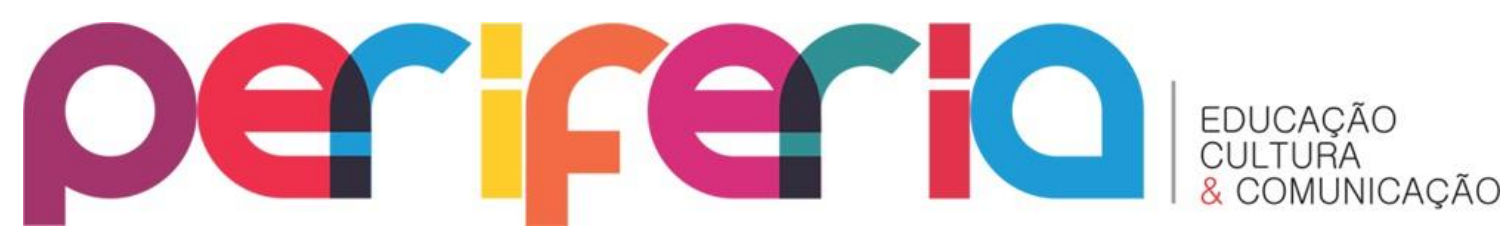

A professora Olga Odete destacou em seu mapa conceitual o elemento "aluno Surdo", e com isso expressou que "no centro o aluno Surdo, porque o aluno Surdo ele que é o sujeito, então tem que estar focado nele, todos os outros. Como é que eu digo? Os trabalhos estão interligados a ele, então ele é o centro" (Professora Olga Odete, entrevista realizada em: 19/03/2015).

Em seu mapa conceitual, seus dizeres estão ancorados na ideia de que a escola precisa reconhecer o aluno Surdo como o objetivo principal do processo escolar. A professora mostra em seu mapa que o ideal seria que $o$ aluno fosse o centro de todo esse processo de escolarização, mas nem sempre os objetivos educacionais com este aluno são alcançados. Inclusive em sua fala percebemos que:

Existe muito aquela questão do professor [do ensino comum] pensar que o aluno é do professor de educação especial e os outros profissionais ainda mais, embora a escola tenha já trabalhado a questão da inclusão, da necessidade de aprender Libras, ofertando algumas oficinas de Libras para toda a escola e a todos os profissionais, ainda assim eles se sentem meio que ausentes. Parece que é o AEE, o professor de educação especial, que é o responsável da comunicação (Professora Olga Odete, entrevista realizada em: 19/03/2015).

Em seu depoimento a professora Olga Odete deixou nítido que existe a omissão por parte de alguns professores do ensino regular em estabelecerem maiores aproximações com o aluno Surdo, porventura este distanciamento, ocorre devido os professores, em sua maioria, não terem conhecimento sobre a Libras e sobre a realidade do aluno Surdo.

Essa necessidade de se conhecer a Libras e o aluno Surdo carece também de ser pensada pelos outros profissionais que constituem a dinâmica da escolarização com este aluno. Assim, Ferreira e Zampieri (2009), revelam que é compromisso da escola, e seus profissionais ouvintes, refletir sobre a escolarização de alunos Surdos, uma vez que estes alunos possuem uma língua diferenciada, por isso, esta língua "deve ser de conhecimento destes ouvintes 


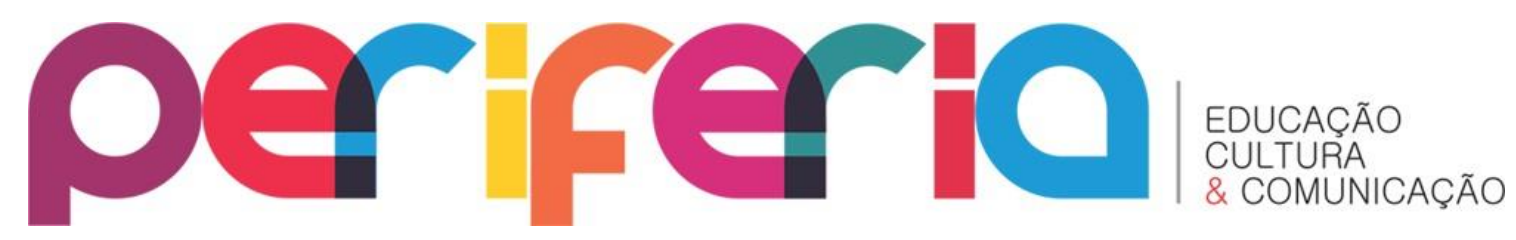

para que assim possam, numa relação dialógica, vir a conhecer as necessidades destes sujeitos" (p. 111).

Portanto, a professora Olga Odete em seu mapa conceitual colocou os “outros profissionais" interligando-os ao professor do ensino regular por meio de linhas pontilhadas, na intenção de revelar que existe um distanciamento ou ausência destes profissionais com a escolarização do aluno Surdo, cabendo ao professor do AEE das SRM ser o responsável por esse aluno.

Diante desta explanação a professora situa em seu mapa o elemento “família", interligando também ao aluno Surdo por meio de linhas pontilhadas, com isso, diz que:

Muitas vezes o maior entrave na inclusão é a própria família, porque a família, às vezes, ela não acredita no próprio filho, no aluno. As vezes a gente chama para a escola, eles não vêm, então por isso que eu coloquei a família mais distante, como se ficasse uma lacuna a ser preenchida. É claro que existem as exceções, que tem pais participativos, que acreditam, mas existem aqueles que simplesmente levam por levar [o aluno Surdo] à escola (Professora Olga Odete, entrevista realizada em: 19/03/2015).

Consideramos rica a fala da professora em relação aos familiares de Surdos, pois seu argumento não traz elementos que generalizam a ausência dos pais, familiares ou responsáveis do processo de escolarização do aluno Surdo. Por sinal, a professora em seu relato ainda enfatiza que existem exceções de pais, que inclusive participam da rotina escolar do Surdo.

A escola além de aproximar os familiares dos alunos Surdos da rotina escolar, para que estes familiares sejam atuantes do processo de escolarização do aluno Surdo, deve promover ações para que estes se apropriem da Libras para o diálogo com Surdos. Para Lacerda e Lodi (2009) “tais crianças permanecem no meio familiar apreendendo coisas do mundo e da linguagem de forma fragmentada, dada a impossibilidade de acesso à língua a qual estão sendo expostas" (p. 14). 


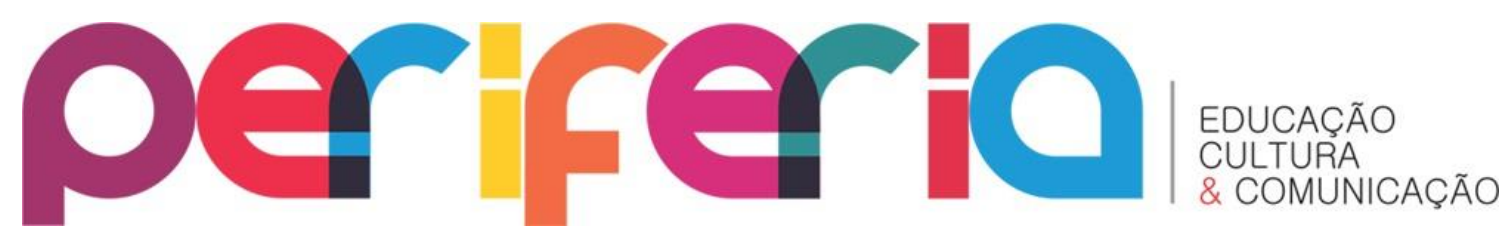

Por isso, acreditamos que a Libras precisa ser o vetor que irá desenvolver o processo de escolarização e irá conduzir o processo ensinoaprendizagem do aluno Surdo. Assim, a professora Olga Odete diz que:

\begin{abstract}
A Libras está mais presente no $\mathrm{AEE}$ porque às vezes 0 professor da sala regular nem sempre tem habilidades em Libras, então ela [a Libras] está mais presente no AEE, até mesmo porque quando o professor precisa comunicar-se com o aluno Surdo, o professor da sala regular, no caso, sempre busca ajuda do professor do AEE (Professora Olga Odete, entrevista realizada em: 19/03/2015).
\end{abstract}

Com base neste argumento, apresentamos os pensamentos de Góes e Barbeti (2009) que refletem que "a inclusão escolar de alunos Surdos vem sendo feita geralmente por sua inserção na rede regular, sem condições diferenciadas de ensino ou ajustes pequenos na organização de serviços complementares" (p. 127). Mencionamos que a Libras é bem mais presente no contexto do AEE em SRM, enquanto que os outros locais da escola, assim como a própria sala de ensino regular, dificilmente lidam com experiências educativas a partir da língua de sinais.

Inclusive na sala regular há a ausência de recursos visuais para o trabalho com Surdos, sendo que tais recursos estão bem mais presentes nas SRM. A este propósito a professora pontuou que:

0 recurso pedagógico existe no $\mathrm{AEE}[. .$.$] está mais presente no$ AEE porque, de certa forma, o professor tem resistência de ir junto conosco, de criar material, de confeccionar, então por isso que eu coloquei um pouco afastado daquele professor, esse professor que eu me refiro é o professor da sala de aula regular (Professora Olga Odete, entrevista realizada em: 19/03/2015).

Em seu mapa conceitual a professora Olga Odete não estabeleceu conexão entre os recursos pedagógicos e o professor do ensino regular, apenas interligou estes recursos ao âmbito do AEE, no caso a SRM, no sentido de frisar 


\section{periferio}

que estes recursos se fazem mais presentes nas SRM e ausentes das turmas regulares com alunos Surdos.

A este respeito Anjos, et al (2014) mencionam que geralmente as SRM possuem "além daqueles recursos disponibilizados pelo MEC, jogos diversificados, quebra-cabeça, brinquedos musicais, revistas em quadrinhos, atividades em Libras, etc, boa parte deles produzidos pelas próprias professoras das SRMs" (p. 96).

É interessante pontuar que os docentes que trabalham em SRM buscam no cotidiano de seus trabalhos produzir materiais pedagógicos para o trabalho com Surdos, porém é possível inferir que, o professor do ensino regular, devido ao excesso de atividades que possui para realizar em seu cotidiano, não dispõe de um tempo específico para confeccionar tais materiais no âmbito escolar.

Não estamos afirmando que os docentes das SRM têm uma carga horária de trabalho mais leve para realizar o trabalho com Surdos, mas que por atuarem com duplas ou trios de alunos Surdos, geralmente encontram um tempo para planejar suas atividades e confeccionar materiais pedagógicos na própria escola; e isso não ocorre em relação ao professor do ensino regular, que não dispõe deste tempo na escola e ainda trabalha com turmas lotadas de alunos.

Em relação ao tempo, a professora destacou que:

O tempo está ligado mais ao aluno Surdo, a Libras e ao próprio $\mathrm{AEE}$, então eu acho assim, que esse tempo é limitado, por exemplo, o professor do AEE é tipo um clínico geral, tem que dar conta de língua portuguesa, de matemática, de Libras e uma série de coisas, atender família e os outros profissionais da escola, enfim, então eu acho esse tempo um pouco distante, porque eu acho ele limitado para tantas atribuições do AEE (Professora Olga Odete, entrevista realizada em: 19/03/2015).

A professora representou o tempo em seu mapa a partir de suas percepções sobre as atribuições que são definidas aos docentes que atuam no 


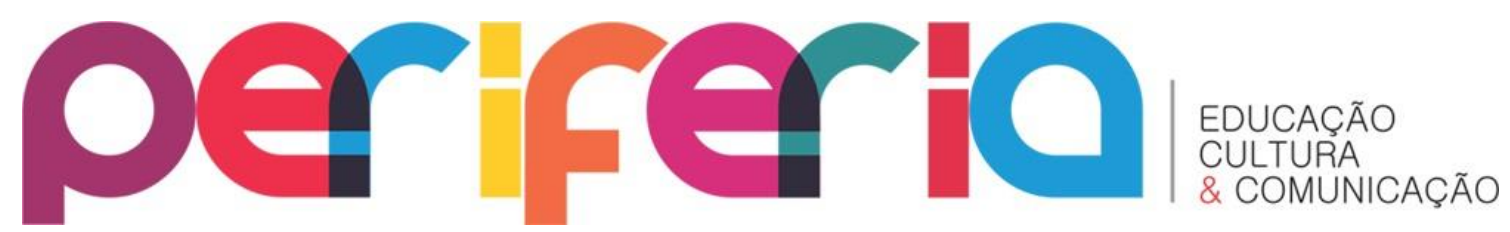

AEE em SRM. ${ }^{5}$ Neste sentido, a atuação do docente do AEE em SRM é análoga a atuação de um clínico geral, ou seja, o professor neste espaço atua com atribuições abrangentes, como: ensinar língua portuguesa, matemática, Libras, orientar os familiares e outros profissionais da escola.

Pensamos que o AEE em SRM destinado ao aluno Surdo precisa ser repensado, pois as atribuições dos profissionais que atuam neste espaço são inúmeras e isso acaba dificultando o processo de escolarização da pessoa Surda. Delevati (2012), menciona que, além destes aspectos, as fragilidades do AEE estão diretamente relacionadas a espaço físico e falta de recursos humanos, para colocar em prática as ações das SRM.

O último elemento representado pela professora Olga Odete em seu mapa conceitual foi sobre o intérprete de Libras. A professora diz que "o intérprete não tem na escola, a seta não interliga porque ele não está presente" (Professora Olga Odete, entrevista realizada em: 19/03/2015). Desta forma, apresentamos uma das problemáticas mais perceptível na "escola inclusiva", no caso, a ausência do profissional intérprete de Libras no contexto de "turmas inclusivas" com alunos Surdos.

Ferreira; Zampieri (2009), mencionam que “o intérprete deve participar da equipe pedagógica no que concerne aos aspectos que garantam o desenvolvimento dos processos de ensino-aprendizagem dos alunos surdos" (p. 110-111). Por isso, mencionamos que, para realizar a inclusão de Surdos, é

\footnotetext{
${ }^{5}$ De acordo com o Art. 13 da Resolução $\mathrm{n}^{\circ}$ 04/2009 são atribuições do professor do Atendimento Educacional Especializado: I - identificar, elaborar, produzir e organizar serviços, recursos pedagógicos, de acessibilidade e estratégias considerando as necessidades específicas dos alunos público-alvo da Educação Especial; II - elaborar e executar plano de Atendimento Educacional Especializado, avaliando a funcionalidade e a aplicabilidade dos recursos pedagógicos e de acessibilidade; III - organizar o tipo e o número de atendimentos aos alunos na sala de recursos multifuncionais; IV - acompanhar a funcionalidade e a aplicabilidade dos recursos pedagógicos e de acessibilidade na sala de aula comum do ensino regular, bem como em outros ambientes da escola; $\mathrm{V}$ - estabelecer parcerias com as áreas intersetoriais na elaboração de estratégias e na disponibilização de recursos de acessibilidade; VI - orientar professores e famílias sobre os recursos pedagógicos e de acessibilidade utilizados pelo aluno; VII - ensinar e usar a tecnologia assistiva de forma a ampliar habilidades funcionais dos alunos, promovendo autonomia e participação; VIII estabelecer articulação com os professores da sala de aula comum, visando à disponibilização dos serviços, dos recursos pedagógicos e de acessibilidade e das estratégias que promovem a participação dos alunos nas atividades escolares.
} 


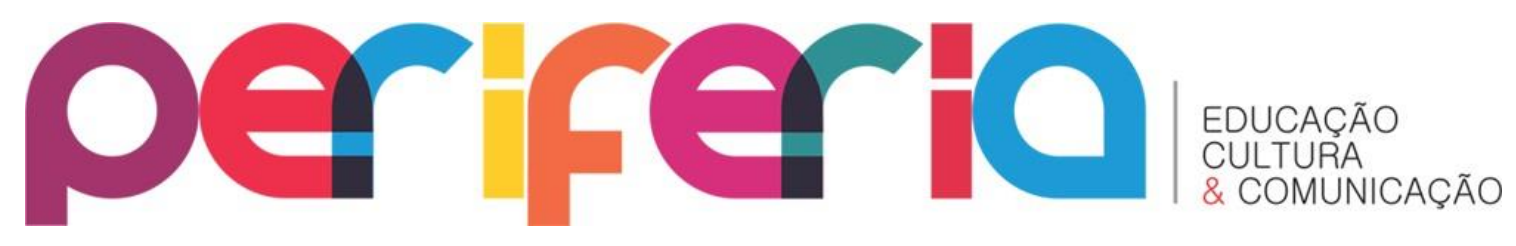

essencial pensar em formas de acessibilidade deste aluno no espaço escolar, no bojo desta acessibilidade encontra-se a necessidade da presença do profissional intérprete de Libras, principalmente a partir do $6^{\circ}$ ano do ensino fundamental.

\section{CONSIDERAÇÕES FINAIS}

Neste estudo buscamos responder a seguinte questão-problema: quais os dizeres de uma professora sobre a escolarização de alunos Surdos em Breves - Pará? Com isso, objetivamos identificar o perfil de uma professora e analisar seus dizeres acerca da escolarização de alunos Surdos que estudam em escola inclusiva em Breves-Pará.

Entre os resultados apontados neste estudo, ressaltamos que: há um distanciamento entre professores do ensino regular, outros profissionais e de alguns familiares com a escolarização do aluno Surdo; a Libras e recursos visuais ou em Libras estão mais presentes no AEE em SRM; o professor de AEE em SRM possui atribuições abrangentes e excesso de funções no trabalho com Surdos; e há a ausência do profissional intérprete de Libras, assim como de alguns familiares de Surdos na escola.

Diante deste contexto indicamos que seja imprescindível pensar em ações educacionais que reconheçam e valorizem os Surdos a partir de suas especificidades linguísticas. A escola precisa criar ambientes linguísticos que oportunizem a comunicação entre Surdos e ouvintes, para que o processo de escolarização de alunos Surdos se efetive de maneira significativa.

Percebemos que a escola, que atualmente acolhe estes alunos em seu contexto, precisa ser repensada a partir da perspectiva do próprio Surdo. A escola não deve apenas se dizer inclusiva, mas necessita ser transformada em uma escola bilíngue, com o compromisso de promover a escolarização de alunos Surdos tendo como principal forma de ensino e instrução a Libras.

Por isso, afirmamos que a inclusão escolar, da forma como vem sendo efetivada, promove o atraso educacional do aluno Surdo, uma vez que a 


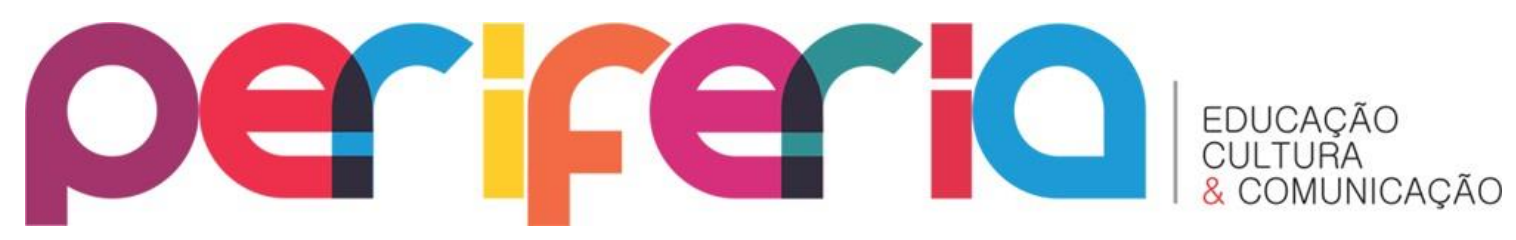

escola não se encontra organizada para receber este aluno em seu contexto. A escola como um todo deve promover ações que priorizem o universo linguístico e comunicacional do aluno Surdo, para que este possa aprender e se desenvolver em um espaço educativo que o respeite em suas diferenças, em uma escola verdadeiramente inclusiva.

As análises feitas neste estudo, evidenciam que o modelo de inclusão educacional vigente em nossa conjuntura precisa ser problematizado, pois pensamos que o ideal seria que os Surdos fossem educados a partir de uma perspectiva bilíngue que vai além do uso e difusão da língua de sinais, visando a garantia de acesso e permanência dos Surdos com seus pares no âmbito escolar. Um ambiente educativo em que o ensino-aprendizagem seja efetivado por meio de ações educacionais que reconheçam os Surdos a partir de suas diferenças linguísticas e comunicacionais.

No processo de escolarização de alunos Surdos o ensinar, o aprender e a Libras devem caminhar de mãos dadas, pois desta forma a escola e, principalmente, seus professores partilharão ideias e dizeres que venham efetivar práticas pedagógicas pautadas na perspectiva bilíngue, contribuindo significativamente com a aprendizagem do aluno Surdo.

\section{REFERÊNCIAS}

ANJOS, H. P. et al (Org.). Tensões no fazer pedagógico: estudando relações entre salas de recursos multifuncionais e salas comuns. In: OLIVEIRA, I. A. (Org.). Práticas de escolarização em salas de recursos multifuncionais: dizeres de professores e alunos. Belém: EDUEPA, 2014, p. 87-101.

BARDIN, L. Análise de Conteúdo. Tradução Luís Antero. Lisboa/Portugal: Edições 70, 2011.

BENTES, J. A. O; HAYASHI, M. C. P. I. Normalidade e disnormalidade: formas do trabalho docente na educação de surdos. Campina Grande: EDUEPB, 2012.

BRASIL. Resolução CNE/CEB 4/2009. Diário Oficial da União, Brasília, 5 de outubro de 2009. Disponível em:

<http://portal.mec.gov.br/dmdocuments/rceb004_09.pdf>. Acesso em: 28 mar. 2017. 


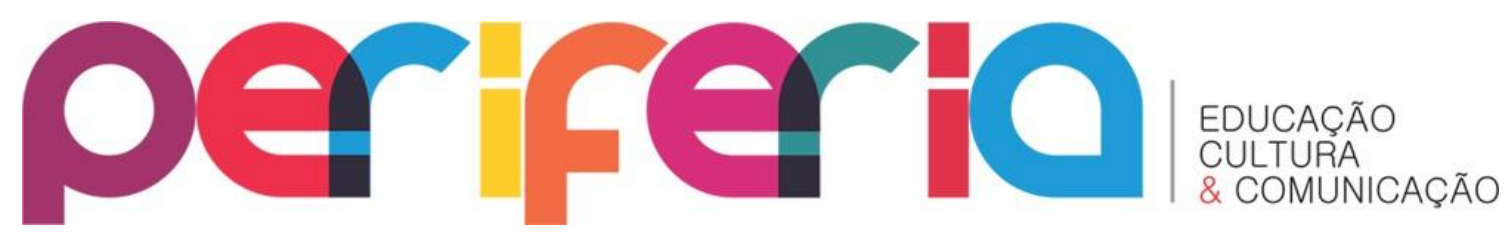

BREVES. Concurso Público - Edital N. ${ }^{\circ}$ 001/2013. Disponível em:

<http://portalfadesp.mentorhost.com.br/midias/anexos/268_edital_01_201 3_pmb.pdf>. Acesso em: 28 mar. 2017.

CAMPOS, M. de L. I. L. Educação Inclusiva para surdos e as políticas vigentes. In: LACERDA, C. B. F. de; SANTOS, L. F. dos. Tenho um aluno surdo: e agora? Introdução à Libras e educação de surdos. São Paulo: EdUFSCar, 2013, p. 37 61.

COMISSÃO DE ELABORAÇÃO DO PLANO MUNICIPAL DE EDUCAÇÃO. Breves-Pará. Documento Base do Plano Municipal de Educação do Município de Breves (2015-2025). 2015, p. 01-324.

DELEVATI, A. de C. Que atendimento é este? As configurações do Atendimento Educacional Especializado na perspectiva da rede municipal de ensino de Gravataí - RS. 2012. 143 f. Dissertação (Mestrado em Educação), Universidade Federal do Rio Grande do Sul, Porto Alegre, 2012.

DORZIAT, A. O outro da educação: pensando a surdez com base nos temas identidade/diferença, currículo e inclusão. Petrópolis, RJ: Vozes, 2009.

FERREIRA, M. C. C; ZAMPIERI, M. A. Atuação do professor ouvinte na relação com o aluno surdo: relato de experiência nas séries iniciais do ensino fundamental. In: LODI, A. C. B; LACERDA, A. C. B; (Orgs.). Uma escola, duas línguas: letramento em língua portuguesa e língua de sinais nas etapas iniciais da escolarização. Porto Alegre: Mediação, 2009. p. 99-112.

GÓES, M. C. R; BARBETI, R. de S. As interações da criança surda no espaço do recreio e sua formação bilíngue. In: LODI, A. C. B; LACERDA, C. B. F. Uma escola, duas línguas: letramento em língua portuguesa. Porto Alegre: Mediação, 2009, p.127-141.

INSTITUTO BRASILEIRO DE GEOGRAFIA E ESTATÍ́STICA (IBGE). Censo 2014. Disponível em: <http://www.ibge.gov.br>. Acesso em: 14 mar. 2015.

LACERDA, C. B. F; LODI, A. C. B. A inclusão de alunos surdos: princípios, breve histórico e perspectivas. In: LODI, A. C. B; LACERDA, C. B. F; (Orgs.). Uma escola, duas línguas: letramento em língua portuguesa e língua de sinais nas etapas iniciais da escolarização. Porto Alegre: Mediação, 2009. p. 11-32.

LUDWIG, A. C. W. Fundamentos e prática de metodologia cientifica.

Petrópolis, RJ: Vozes, 2009.

MINAYO, M. C. S. Ciência, Técnica e Arte: O desafio da pesquisa social. In: MINAYO, M. C. S. (Org.). Pesquisa Social: Teoria, Método e Criatividade. Petrópolis: Vozes, 1994. p. 9-21. 


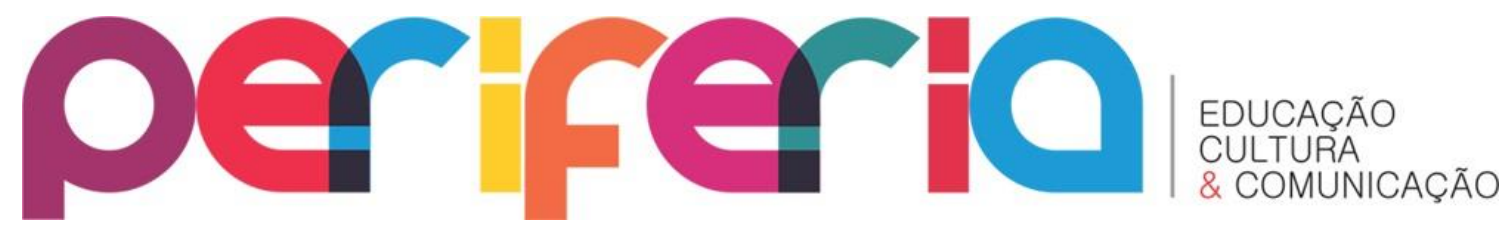

MOREIRA, M. A. A teoria da aprendizagem significativa e sua implementação em sala de aula. Editora da Universidade de Brasília: Brasília: 2006.

MOREIRA, M. A. Aprendizagem significativa: a teoria e textos complementares. São Paulo: Editora Livraria da Física, 2011.

MOREIRA, M. A; MASINI, E. F. S. Aprendizagem significativa: a teoria de David Ausubel. São Paulo: Moraes, 1982.

OLIVEIRA, I. A. de. Saberes, imaginários e representações na educação especial: a problemática da "diferença" e da exclusão social. Petrópolis, RJ: Vozes: 2004.

TAVARES, R. Construindo mapas conceituais. Ciências \& cognição, 2007; Ano 04, v. 12, p. 72-85. Disponível em http://www.cienciasecognicao.org. Acesso em: 05 dez. 2014. 